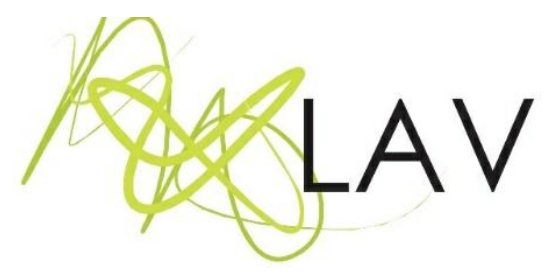

\title{
Espaço Ruínas: do valor de exibição para o valor de ocupação/acontecimento
}

\author{
Ruins Space: from exhibition value to occupancy/event value
}

Roberta Stubs

Universidade Estadual de Maringá

Cleberson Diego Gonçalvesii

Universidade Estadual de Maringá

\begin{abstract}
Resumo
Este artigo tem como dispositivo de reflexão a ocupação/exposição Presenças Plurais, que ocorreu em 2019 na Universidade Estadual de Maringá. A partir desse evento, pensa-se sobre a curadoria como trabalho de arte (HOFFMANN, 2004) e, a partir da análise institucional (BAREMBLITT, 2002) e da crítica institucional da arte (FRASER, 2005), situase localmente o valor de exibição da arte (FREIRE, 1999), analisando seus desdobramentos enquanto um agenciamento coletivo de enunciação (DELEUZE; GUATTARI, 1995). O tensionamento entre exposição e ocupação será explorado a fim de pensar a arte enquanto modo de organização coletiva que, para além do cubo branco, ganha corpo como acontecimento movido por alianças e afinidades desejantes. Por fim, em um cruzamento entre o campo da arte e o da educação, reflete-se sobre o papel do artista-professor, que vê o ensino da arte como proposição artística, bem como um dispositivo para uma educação menor (GALLO, 2002).
\end{abstract}

Palavras-chave: Curadoria propositiva, devir artista-professor, arte contemporânea.

\begin{abstract}
This article will have as a reflection device the occupation / exhibition Plural Presences, which took place in November 2019 at the State University of Maringá. We will take this event as an analyzer to think of curation as a work of art (HOFFMANN, 2004), and, based on institutional analysis (BAREMBLITT, 2002) and institutional criticism of art (FRASER, 2005), to place the value of art exhibition (FREIRE, 1999) analyzing its unfolding as a collective enunciation agency (DELEUZE; GUATTARI, 1995). The tension between exhibition and occupation will be explored here in order to think of art as a mode of collective organization that, in addition to the white cube, gains body as an event driven by alliance and desiring affinities. Finally, at a crossroads between the field of art and the field of education, we begin to think about the role of the artist-teacher who sees art teaching as an artistic proposition and as a device for a lesser education (GALLO, 2002).
\end{abstract}

Key words: Purposeful curation, artist-teacher's becoming, contemporary art. 


\section{Introdução}

O que se passa entre os corpos numa ocupação é mais interessante que a própria ocupação.

(TIQQUN, 2019, p. 15).

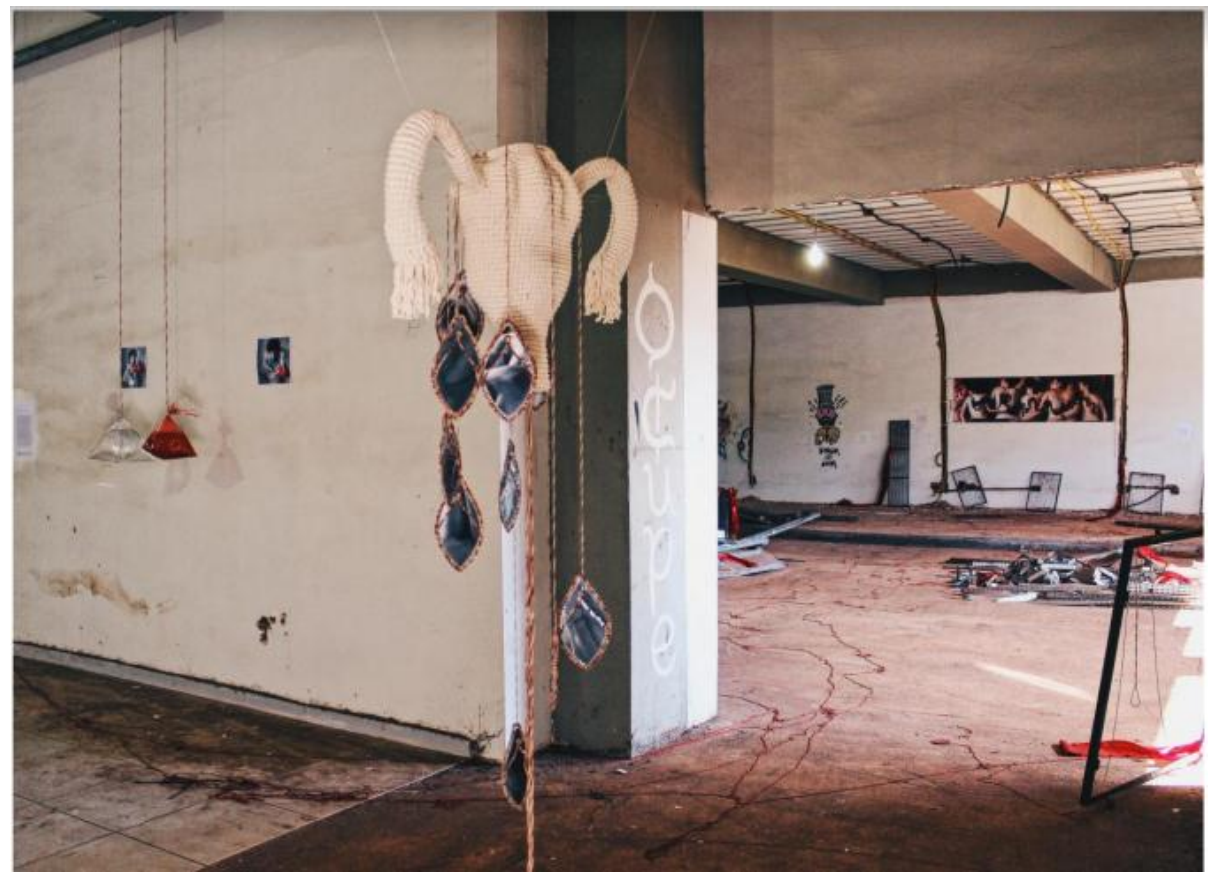

Figura 1: Espaço Ruínas - Exposição Presenças Plurais, 2019, no detalhe - Beatriz Nolli, Tecitura do meu corpo-mulher, Escultura de crochê com linha de algodão cru. Ao fundo, trabalho de Barbara Boer e Gabriel Batista - presentes na exposição. Imagem do catálogo Exposição Presenças Plurais. In: I Seminário de Artes Visuais da UEM. Corpo a corpo: Presenças Plurais.

Fonte: Roberta Stubs, 2019, arquivo pessoal das autoras.

Forjamos no pó, nos ferros, no cimento e nos entulhos o nosso território móvel, de trocas, afetos e insurreições. Deixamos marcas e resíduos daquilo que era - e talvez ainda seja - um espaço de desejos e sonhos para alguma possível utilização. Nossas ações deram forma à nossa fragilidade humana, levaram-nos a observar a perda e a destruição, transformamos algo que estava aos nossos olhos em ruínas, um cenário sócio-político atual de solidão, vigilância, fragilidade das histórias humanas e também em vontade de sobreviver. Os escombros que desejamos reinventar e levantar diante da existência física e ideológica das fronteiras, das pluralidades, daquilo que é legal e ilegal, de pertencimento e isolamento.

Criamos um desejo de sobreviver, de reinventar e de marcar as 'paredes' de nosso local de vida, trabalho, atuação e nossas próprias demandas, negadas ou negligenciadas pelas instituições que capitalizam os saberes, que transformam prédios de sonhos em ruínas, corpos em ruínas, sociedades, comunidades, tribos em resquícios de algo que um 
dia se poderá permitir viver. Encontramos nos destroços, em suas fissuras entre os escombros, uma possibilidade artística, pedagógica, ativista e de atuação de professoras/artistas e curadoras que mediaram novos saberes produzidos num ambiente, antes, inerte.

Tudo começou com um desejo já antigo de encontrar, na universidade, um espaço adequado para expor trabalhos e experimentações artísticas feitas pelas alunas do curso de Artes Visuais - UEM. Um desejo que sinaliza uma vontade de existir com mais dignidade e vigor dentro do campus universitário que quase sempre reserva à arte corredores, halls de entrada e espaços destinados a outras finalidades que não à arte. Temos aqui um primeiro analisador institucional, ou seja, o pouco investimento público em arte e cultura, áreas tidas como secundárias e pouco importantes.

Nesse contexto, não tínhamos um cubo branco para expor nossos trabalhos, não havia nenhum espaço pronto que moldasse e garantisse a segurança de nossas experimentações e objetos. Nós não tínhamos uma tenda, como a que Gustave Courbet utilizou em 1855, durante a 'Exposição Universal' ao lado do pavilhão das Belas-Artes para expor obras que haviam sido selecionadas, mas que o artista recusou-se a mostrar por julgar que "seus quadros teriam sido dispersos em meio à abundância indiferenciada dos objetos comparáveis" (BOIS, 2012, p. 122). Tínhamos apenas o desejo e a necessidade de expor nossas ideias artisticamente.

Diante dessa falta e desse engessamento institucional, restou-nos inventar saídas. Inspiramo-nos na radicalidade da vanguarda modernista cujos artistas se reuniam coletivamente em torno de um desejo de produzir e pensar a arte, forjando espaços de exposição e trocas mesmo que temporários e provisórios. A deriva situacionista se configurou nesses moldes, algumas ações dadaístas também aconteciam em lugares abandonados nos quais os artistas se encontravam para ações efêmeras que logo se dissipavam no espaço provisório do encontro. Se o espaço se desfez ao ser evacuado, o tempo, por sua vez, segue reverberando na duração dessas ações que se atualizam na medida em são revividas e reexperimentadas. Encontramos na arte contemporânea muitas formas de atualização dessa proposta artística que, no lugar de objetos artísticos, tende a priorizar as trocas e a dinâmica relacional e intersubjetiva entre o 'público' e a obra. Voltada muito mais para o processo do que para um resultado final, esse tipo de proposição artística tem seu foco nas trocas, afetos, movimentos inventivos e desejantes até desviantes que constituem o processo criativo propriamente dito. 


\section{A arte como modo de organização}

Foi na disciplina de 'Estudos e Planejamentos de Espaços Expositivos' indicada para o $4^{\circ}$ ano de Artes Visuais da Universidade Estadual de Maringá que o desejo de uma exposição começou a ganhar materialidade, instaurando e percorrendo brechas e lacunas nessa trama institucional que nos amarra por fora e por dentro. Debatendo-nos contra algumas amarras institucionais, apoiamo-nos no coletivo para fazer acontecer esse projeto que se mostrava mais impossível do que viável. A figura da artista-professora foi aqui fundamental para imprimir um tônus artístico no que poderia ser apenas uma prática pedagógica. Retomaremos essa figura mais adiante, quando falarmos da curadoria também como proposição artística. Por ora destacamos o protagonismo das alunas que encamparam esse projeto na incerteza do que de fato iria acontecer. Afinal, essa exposição/ocupação inaugurou um formato de exibição nunca antes vivido no curso e na universidade. Um saber fazer, estar no mundo, orientar-se nos imprevistos, quando não há regras precisas, criar na precariedade e imprevisibilidade novos modos de existir e fazer arte. Foi, portanto, uma experiência inédita que explorou o trabalho de arte não como prática individual, circunscrita à subjetividade e experiência da artista, mas a teve como um modo de organização da ordem do coletivo.

A arte como modo de organização é uma expressão cunhada por Marcelo Expósito (2014), para o qual a arte não se limita a produção de um objeto, material ou imaterial, tampouco a uma ideia. Para o autor, estamos produzindo coisas da ordem do tangível e também do intangível:

Um tangível que é este dispositivo para poder cooperar, para poder produzir conhecimento cooperativamente. E estamos produzindo um intangível, que é o próprio fato de cooperar produzindo conhecimento, o conhecimento que se produz cooperativamente (EXPÓSITO, 2014, s/p).

Duas frentes de análise se abrem aqui: o tangível que seria a exposição/ocupação propriamente dita e o intangível tomado por nós tanto como um desejo instaurador de mundos que moveu a exposição quanto como um campo de intensidade e trocas afetivas, que seguiu ressonando durante e após a exposição/ocupação. Um possível está sendo criado, uma normalidade desafiada, um estado que é de rebelião e que coincide com o próprio estado-arte. A ocupação também expressa o princípio de que o como se ensina é o que se ensina.

O espaço tangível seria então a primeira dificuldade artística e pedagógica encontrada, mas é a partir dele que um ciclo de resistência começa a ser pensado e planejado, o espaço precisa ser ativado, ele é um ponto em transmutação, esperando que 
as pessoas o ocupem e desenhem sobre ele novas perspectivas. Foi aí que nos colocamos a refletir sobre a seguinte pergunta: Seria o espaço um demarcador de distâncias ou um campo amplo para ser preenchido? A partir daí desdobramos algumas reflexões:

Pensando que todo espaço pode ser atravessado e ocupado, é possível entendê-lo como um lugar a ser aumentado por vidas, trocas e afetos. Afinal, muita coisa pulsa entre um ponto e outro da geografia da vida, e pensando assim, talvez o espaço seja um corpo vivo que precisa ser ativado. Com esse olhar, imprimimos em nossa pele um desejo de acontecimento. Algo como uma vontade de ocupar o espaço com a potência da presença, capaz de conferir ao corpo da paisagem a vitalidade das trocas e afetos (STUBS, 2019, p. 2).

Esse espaço em ruínas se instala como materialização e produção de significantes para nosso processo de criação. Ele se mostra como um processo de descontinuidade nos modos de pensar e praticar essa realidade as quais estamos sujeitas. Tomada como princípio para fazer e pensar arte, esse espaço permitiu relações conosco e com outras pessoas, com o corpo, objetos, desejos, sendo todas essas inscrições realizadas de uma forma diferente. Esse acontecimento descontínuo ativou alterações que nos fazem observar o modo como nos compreendemos. Produzimos subjetividade e lançamos subjetivações, um devir.

A universidade se abriu para nós como um local que deveria então ser habitado pela potência da presença, um local que acomodasse nossos pensamentos, transbordamentos e propostas, uma forma diferente de praticar o cotidiano. No campus sede da UEM, em Maringá, muitos blocos de sala de aula estão abandonados, começaram a ser construídos e tiveram sua execução cancelada devido a problemas burocráticos, o que fez com que muitas construções 'fantasmas' desenhassem uma nova paisagem no campus, de abandono e descaso. Esses escombros, ossos de um corpo em decomposição, apresentaram-se para nós como possibilidades, como um lugar a ser ocupado e transformado em um território que abraçasse os afetos dispostos àquela ação.

Um desses blocos fica ao lado do departamento ao qual o curso de Artes Visuais é anexado, e foi ele que acomodou o formato de nossa exposição. Espaço Ruínas, apelido carinhoso dado a esse bloco com cerca de 50 salas de aula, 4 andares e um auditório com capacidade para aproximadamente 100 pessoas. Abandonado há 10 anos, o Ruínas segue acumulando poeira, descaso e marcas do tempo. Porém, em novembro de 2019, por quatro dias consecutivos, a poeira teve que dividir espaço com as mais de 400 vidas que oxigenaram um local até então abandonado. Vivo, o corpo arquitetônico do Espaço Ruínas pulsou, na medida em que nossos visitantes circulavam pelas salas e corredores para ver 
os 31 trabalhos artísticos que compuseram a exposição e se encontravam distribuídos no térreo do Ruínas. Pode-se dizer que:

Muito além do campo da arte, a exposição/ocupação Presenças Plurais foi um acontecimento que iluminou questões variadas, como o descaso do poder público com a esfera da educação, a precariedade dos cursos novos que carecem de estrutura, a ausência de locais de convívio e troca na universidade, a escassez de estruturas destinadas à arte e à cultura (STUBS, 2019, p. 2).

Presenças Plurais ${ }^{1}$ se tornou então uma ação política-artística, por meio de um desejo coletivo que se ativou como força motriz para ocupar e problematizar a vida e a própria realidade. Inventamos nesse espaço abandonado uma nova realidade possível, um espaço de intimidade, onde nossos trabalhos, experimentações e desejos alcançaram novos voos. A arte foi tomada aqui em sua função de invenção de modos de organização (EXPÓSITO, 2014), enlaçando a dimensão tangível e material e a dimensão intangível das forças mobilizadas para que a proposta se efetivasse.

A arte se apresentou como gesto vivo nessa insurreição, um vetor possível de fuga, porque a vida, mesmo entre os escombros, emerge como indomável, porque é força vital que pulsa uma potência de diferenciação contínua, de múltiplas dimensões de desejo. Estávamos ali por inteiro, com tudo o que cada uma tinha e carrega - a ancestralidade, as lutas, os buracos, os traumas, as dores, as alegrias, a cor, o gênero, as histórias e as vergonhas. Fomos organizadas por meio da arte, em sua tangissidade e intangissidade a ocupar primeiramente nosso próprio corpo como um território real e legítimo. Como corpo coletivo, ganhamos força e forjamos um território de arte. Nas ruínas de uma instituição pública de ensino, alunos e professores canalizaram seus desejos e sua força de trabalho para dar forma ao que até então era um espectro de imaginação. Fizemos pulsar um espaço esquecido, forjamos um território nômade ocupado e ativado por uma exposição de arte temporária.

A especificidade da arte enquanto modo de expressão e, portanto, de produção de linguagem e de pensamento é a invenção de possíveis - estes ganham corpo e se apresentam ao vivo na obra. Daí o poder de contágio e de transformação de que é portadora a ação artística. É o mundo que está em obra por meio desta ação. Não há então porque estranhar que a arte se indague sobre o presente e participe das mudanças que se operam na atualidade (ROLNIK, 2006, p. 2).

\footnotetext{
${ }^{1}$ Vale pontuar que esta exposição é um desdobramento da disciplina de Estudos e Planejamentos de Espaços Expositivos, conduzida pelas autoras deste artigo. Importante dizer também que a exposição/ocupação integrou o I Seminário de Artes Visuais: corpo a corpo, presenças plurais, que esteve sob coordenação do Prof. Dr. Vinicius Stein. A exposição foi a plataforma escolhida por nós para reunir os trabalhos artísticos produzidos por alunos, professores e demais artistas da cidade de Maringá e região, que se inscreveram para participar do Seminário.
} 
Tomamos o /im/possível como coeficiente artístico (STUBS, 2019) e inventamos um espaço para habitar. Nossos corpos vibraram com aquela realidade inventada por nós. A materialidade do projeto continha a potência de nossos sonhos. Imprimimos na aridez de nossa realidade institucional uma dobra inventiva que não cessava de se desdobrar dentro e fora do corpo coletivo que fez acontecer esse projeto. Ficcionalizamos o real para criá-lo sob outro umbral de possibilidades e ficamos contagiados pela potência criativa que daquele bloco ressoava.

O artista Daniel Buren (2001, s/p) afirma que, muitas vezes, "é verdade que a exposição se estabelece como seu próprio assunto, e o seu próprio assunto como um trabalho de arte" ${ }^{\prime 2}$. É assim que entendemos essa experiência coletiva que compartilhamos com vocês neste artigo. A exposição/ocupação Presenças Plurais por si só se configura como uma proposição artística que teve como propósito maior ser ponto de coalizão de trabalhos de outros artistas. Presenças Plurais foi o termo que abrangeu a multiplicidade dessa proposta e dos trabalhos reunidos.

Sob o umbral da pluralidade, reunimos 31 trabalhos, que eram em sua maioria produções de alunas e ex-alunas do Curso de Artes Visuais da UEM. Artistas de outros cursos e instituições também marcaram presença, sendo dois deles artistas e professores. Vídeo, desenho, pintura, fotografia, escultura, instalações e performances audiovisuais. Múltiplas linguagens e diferentes perfis de artistas que, gentil e corajosamente, aceitaram o risco de entrar conosco nessa aventura de criar/ocupar um bloco entre poeira, dejetos e resíduos de construção. O desejo por uma vida mais livre, mais ética e em sintonia com outros povos foi perceptível em muitos dos trabalhos selecionados, que tiveram como eixo "as diferenças, seus corpos, suas urgências e as linguagens utilizadas para se reinventar em um momento onde o fascismo adentra as brechas mais importantes de nosso país" (STUBS, MADDOX, 2019, p. 3).

Um dos vários impulsos que nos levaram a criar territórios onde a dissidência, as poéticas e a arte ganhasse espaço, é o fato de superarmos a "anestesia da vulnerabilidade ao outro, própria da política de subjetivação em curso" (ROLNIK, 2006, p. 2), e assim nos sentirmos vivos. Presenças Plurais foi um corpo vibrátil, que fez implodir nossos locais de existência, deixando à mostra os contornos cambiantes de nossa subjetividade que nos interessa muito mais como força desejante do que como força reacionária.

2 BUREN, D. Exposição de uma exposição. In: Sí, tiene em português! 2015. 


\section{Do valor de exibição para o valor de ocupação/acontecimento}

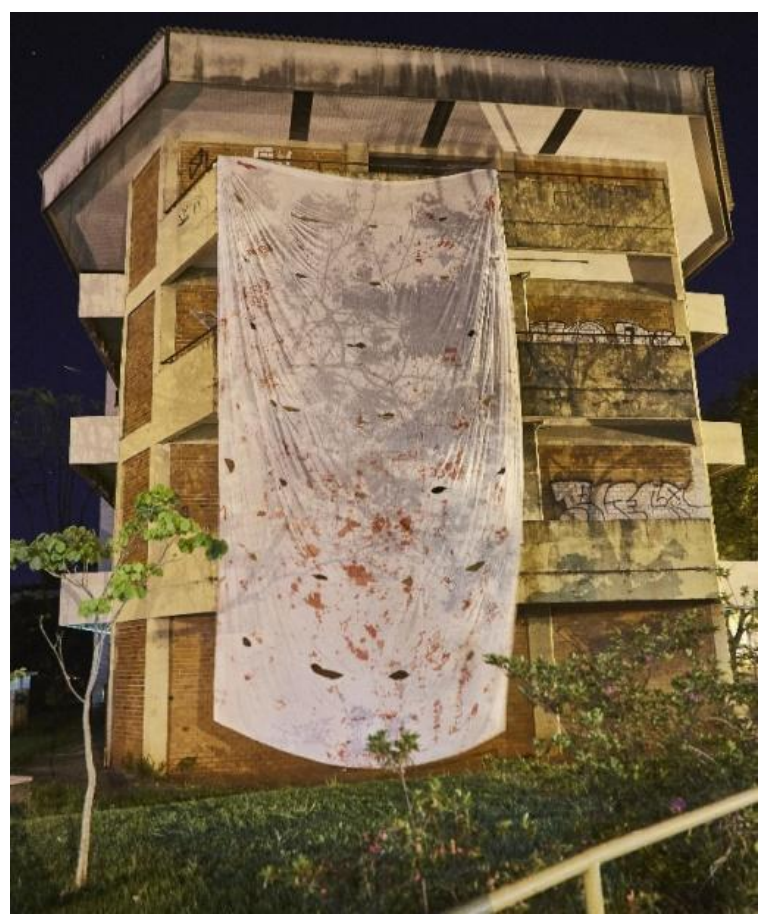

Figura 2: Bandeira demarcando o espaço Ruínas - Exposição Presenças Plurais, 2019. Fonte: Imagem do catálogo Exposição Presenças Plurais. In: I Seminário de Artes Visuais da UEM. Corpo a corpo: Presenças Plurais. Foto de Cesar Augusto Silva.

Do alto do quarto piso de um bloco abandonado, ateamos nossa bandeira de pirata: um tecido branco com respingos, escritos e bordados em vermelho. Com cerca de $30 \times 30$ metros, foi essa a maneira como sinalizamos que aquele bloco era agora o Espaço Ruínas, lugar de encontro, trocas e afetos. Ocupamos e ativamos esse lugar como uma produção de arte coletiva, mais aberta ao uso, à apropriação e à participação. Foi então que o espaço ganhou força estética e ultrapassou o valor de exibição ao se materializar também enquanto acontecimento artístico.

No livro Poéticas do Processo, Cristina Freire (1999) esboça alguns comentários sobre o valor de exibição da obra. Em um diálogo com Walter Bejnamin, a autora afirma que o 'batismo' de um trabalho artístico se dá quando ele é exibido, aspecto que confere legitimidade institucional à obra, algo como uma prova de que determinados trabalhos existiram e foram vistos. O artista Daniel Buren (2001, s/p) afirma desconfiado que "tudo que o museu mostra só é considerado e produzido tendo em vista sua colocação aí", acenando para a necessidade de uma crítica institucional da arte. Desse modo, temos aqui uma dose de ambivalência que, em um só tempo, reconhece a legitimidade de museus e outros espaços de exibição, e questiona o demasiado poder conferido aos museus, galerias e outros espaços institucionais de arte como definidoras do que é ou não arte. Caímos no 
paradoxo de contestar o sistema que valida e confere o valor de exibição e de defender esses espaços como necessários.

Vale retomar aqui as vanguardas modernistas, principalmente as tendências antiarte como o dadaísmo que, ao apostar na proximidade entre arte e vida, criticavam com veemência a institucionalização da arte que, no entendimento deles, distanciava as pessoas da arte. De acordo Andrea Fraser (2005), essas tendências visavam abolir e escapar do sistema da arte que colocava o mercado antes da liberdade e da produção artística. Tal crítica é bastante válida, mas pode ser também uma postura estéril quando, no ensejo de criticar uma instituição, não apresenta nenhuma saída ou linha de fuga, ou ainda, quando não compreende que a instituição não está separada de nós. Segundo a autora,

Toda vez que mencionamos a 'instituição' como algo distinto de 'nós', executamos nosso papel na criação e perpetuação de suas condições. Evitamos as ações contra ou a responsabilidade pelas cumplicidades, compromissos e censuras - acima de tudo autocensuras - cotidianos que são direcionados por nossos próprios interesses no campo e pelos benefícios que dele derivam. Não é uma questão de dentro e fora [...] Não é uma questão de ser contra a instituição: Nós somos a instituição. É uma questão de que tipo de instituição somos, que tipo de valores institucionalizamos, que formas de práticas remuneramos, e a que tipos de recompensas aspiramos. Por ser a instituição da arte internalizada, incorporada, e representada por indivíduos, estas são as questões que a crítica institucional demanda que perguntemos, sobretudo, a nós mesmos (FRASER, 2005, p. 186-187).

Ok, nós somos a instituição. No entanto, temos em nosso repertório as contribuições da crítica institucional e entendemos que é de dentro desse lugar que possuímos também uma potência instituinte de subverter a lógica engessada da instituição para agenciar dentro dela linhas de fugas que deem vazão às forças que escapam ao endurecimento institucional. Segundo Baremblitt (2002, p. 157), "os processos instituintes são mobilizados por forças produtivo-desejante-revolucionárias que tendem a transformar instituições como parte do devir das potências e materialidades sociais". São essas forças que tensionam os limites de um território dado para ressignificá-los em territórios outros. Enquanto força que cria seus próprios territórios de vida, somos a instituição na medida em que desobedecemos algumas regras para forçar que elas sejam revistas. Somos a instituição quando localizamos suas fronteiras para ultrapassá-las.

Um caso exemplar no Brasil foi a arte postal que, na década de 1970, fez do correio o suporte privilegiado da arte. Nessa proposição, assim como no uso de arte Xerox, pela sua possibilidade de reprodução rápida e fácil, algumas barreiras institucionais da arte 
foram borradas e expandidas. A criação de uma rede onde emissor, receptor, mensagem e suporte constituíram um sistema de arte fora das instituições tradicionais como museu e galeria, assim como o poder de circulação e abrangência territorial da arte postal forçaram os próprios museus e galerias a se adaptarem a esse novo formato. Na esteira do que já vinha acontecendo após as questões levantadas pela arte conceitual e sua desmaterialização do objeto da arte (LIPPARD; CHANDLER, 2013), o papel do artista, do público e das instituições "tiveram que ser repensadas a partir de outro paradigma artístico" (FREIRE, 1999, p. 40). Novas formas de documentar, catalogar, preservar, expor e ocupar precisaram ser criadas.

No caso, somos a instituição quando ocupamos o que antes estava abandonado e ativamos esse espaço com a força inventiva de nossos desejos de compartilhamento e troca. Tendo em vista a ausência quase total de espaços destinados à exibição de trabalhos artísticos na universidade, em nossa realidade institucional, ter um posicionamento crítico implica na reivindicação e criação desses espaços. O valor de exibição é aqui uma luta política, afinal, entendemos que halls de entrada, corredores, e mesmo museus históricos e/ou de ciências naturais não dão conta de acolher as demandas da arte contemporânea. O ideal do cubo branco passa bem longe de nossa realidade, e romper com esse parâmetro é condição sine qua non de exposição. O valor de exibição carrega para nós uma dimensão política de visibilidade e de demarcação de território de vida e existência. Ter um espaço de exibição dos trabalhos foi uma janela para que o Curso de Artes Visuais se presentificasse no território universitário. Essa exibição sinalizou tanto a falta de estruturas destinadas à arte e cultura dentro do campus, quanto, principalmente, nosso desejo de instaurar esses espaços de troca e produção.

Dilatamos o termo valor de exibição para seu nexo intangível. Exibir aqui foi existir pelas brechas das instituições; foi inventar um lugar que existia enquanto força desejante, mas não enquanto materialidade concreta. Essa força foi a face mais poderosa desse projeto. Da ordem da exuberância, ela fez da exposição um acontecimento ético-estéticopolítico. Conferiu carne àquilo que poderia ser apenas palavra. Presenças Plurais foi corpo vivo e coletivo, dispositivo para encontros, trocas e transbordamento.

O próprio Espaço Ruínas se alterou radicalmente dentro da Universidade e de si mesmo. Isso revela que os espaços que não eram conhecidos ou que não eram habitados passaram a ser conhecidos e habitados de outro modo. Esses lugares de exceção implicam não só em uma reversão da espacialidade e dos tipos de vínculos que as pessoas criam entre si, como também em uma reversão no tipo de conhecimento que é produzido a partir desse vínculo. É nesse momento que outro conhecimento é questionado: o conhecimento 
normal, o conhecimento das estruturas de poder, das estruturas de dominação. No caso do cubo branco, um questionamento de quem pode estar ali expondo e visitando, da arquitetura, entre outros. Então esse padrão de pensamento normal é ironizado e subvertido, desestabilizando tanto esse modo de pensar como também as figuras de autoridade associadas a ele.

Mais do que uma exposição, falamos aqui de uma ocupação artística que, tal qual um agenciamento coletivo de enunciação, foi movida por um desejo comum de acontecer e existir. Agenciamentos coletivos de enunciação como devires imperceptíveis, mutações afetivas, um concerto polifônico de vozes (GUATTARI; ROLNIK, 1996). Com Deleuze e Parnet (1998, p. 88), aprendemos que "um agenciamento é uma multiplicidade [...] a única unidade de um agenciamento é o co-funcionamento", e este se faz por simpatia, por contágio e alianças. Como multiplicidade, muitas vozes, desejos, mãos e corpos se aliaram para instaurar coletivamente essa proposição. Varremos, limpamos, tiramos entulhos. Contatamos pessoas responsáveis pela instalação de luz elétrica e pela segurança do espaço. Tudo para fazer acontecer. Grupos de alunos trabalharam arduamente no desenvolvimento da identidade visual da exposição, no projeto de expografia do espaço, na organização de visitas mediadas, na divulgação da exposição pelo campus, na curadoria das obras a serem expostas. Prego, fita dupla face, vassoura, escada, sorrisos, cansaço, Coca-Cola, bolacha, domingos na universidade e um desejo comum de inventar no mundo um espaço outro de troca, encontro e existência.

Com a exposição montada, o fluxo de pessoas no Espaço Ruínas ficou bastante grande. As obras ali expostas viraram vetores para o diálogo entre turmas, cursos, professores e pessoas diversas. O espaço passou a ser ponto de encontro, ocupado constantemente por pessoas que transitavam alegres pelos corredores e que ficavam horas a conversar na frente do bloco. Uma força para além da exposição ganhava passagem ali. De exposição para ocupação, foi essa a virada que nos fez perceber que algo maior estava acontecendo. Havíamos ativado um espaço cultural importante. Por quatro dias, mais de 400 pessoas circularam pelo local para verem os trabalhos expostos e também para se encontrarem. Visitas mediadas foram agendadas com alunos do Ensino Público da cidade. Estudantes de artes visuais trabalharam como mediadores, e uma integração entre os diferentes anos do Curso aconteceu naturalmente. No período da noite, rodas de conversas espontâneas e performances aconteciam com garantia de público e debate. 


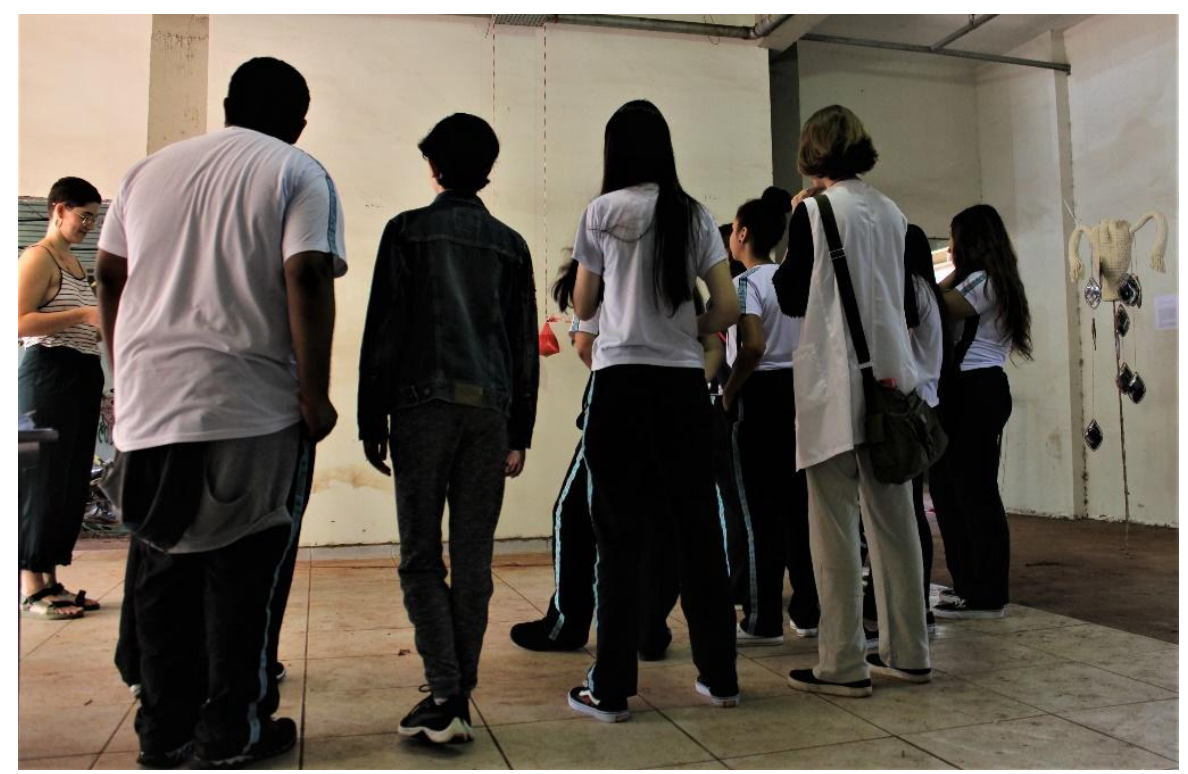

Figura 3: Mediação com alunas de colégio visitante na Exposição Presenças Plurais realizada no Espaço Ruínas em 2019.

Fonte: Roberta Stubs, 2019, arquivo pessoal das autoras.

Segundo Basbaum (2013), esse tipo de experiência artística (podemos pensar também nos coletivos e espaços de arte independentes) nos faz pensar a sociabilidade e os agrupamentos não somente a partir de demandas burocráticas,

Mas sim por essas chamadas políticas da amizade, pela construção de outros laços de trabalho. Amizade não simplesmente fraternal, não aquela amizade cristã, mas a amizade mesmo na sua dimensão política, que leva a construção de um espaço e diferença, um espaço de confronto. Isto agrupa mesmo, isto cria convergência para o novo modo de trabalho, para todos os aspectos ligados à construção de grupos, de espaços de convívio, espaços de aliança, de afinidades (BASBAUM, 2013, p. 123).

Quando uma ocupação ocorre, um desejo comum também é instaurado. Desse modo, nossa ocupação se tornou inventiva e organizada em forma cooperada. Como Kunsthaus Tacheles, um edifício em ruínas da conhecida rua Oranienburger, em Berlim Alemanha - que se tornou o centro cultural alternativo mais famoso do país, abraçando artistas e obras que não 'atendiam' às normas de um cubo branco, um edifício ocupado desde a queda do Muro de Berlim. Tal como nossa exposição/ocupação, essa experiência coletiva, como forma alternativa de organização e gestão coletiva do espaço, é validada em si mesma, pois pratica novas formas de vida, possibilita um sentido construtivo comum que inspira e ativa dispositivos de resistência.

Um trabalho bastante inspirador nesse sentido foi o Arte Ocupação, uma experiência propositiva realizada em algumas Escolas Públicas da cidade de Curitiba, ocupadas por secundaristas no ano de 2016 como forma de se manifestarem contra o desmonte e a 
precarização do Ensino Público. Coordenado pela artista Mila Jung e, em parceria com outros artistas da cidade, o Arte Ocupação realizou

[...] oficinas, ações, relatos, debates, roteiros, entrevistas, traduções de textos, reuniões e finalmente produziu trabalhos, audiovisuais e sonoros, constituindo uma rede de ações/situações que problematizam a experiência desse agrupamento (JUNG, 2018, p. 27).

Tal proposição nos interessa muito pela sua potência de transformação, resistência e produção de territórios de vida, posto que toma a arte como modo de organização capaz de agenciar uma subjetividade política, crítica e inventiva.

\section{Notas sobre a curadoria como proposição artística}

Pontuamos no início deste artigo que a ideia da exposição/ocupação Presenças Plurais surgiu na disciplina de Estudos e Planejamentos de Espaços Artísticos. Tal módulo é obrigatório para as alunas do quarto ano de Artes Visuais e se propõe a entender a história das exposições, abordando também os vários momentos e modos de se fazer curadoria, expografia e mediação. Enquanto professoras dessa disciplina, poderíamos ter seguido inúmeros caminhos pedagógicos, mas optamos por assumir uma postura de artista-professoras para extrair dessa disciplina uma potência que extravasasse do pedagógico para o artístico. Queríamos falar de arte por meio da arte, falar de exposições realizando uma exposição e mobilizando todos os agentes envolvidos nesse projeto também enquanto prática e experiência. Ter a experiência de realizar uma exposição era para quase todas as alunas envolvidas uma grande novidade, sendo também um grande desafio. Porém, mais do que o elemento novidade, a questão que nos interessava partia do entendimento que compreende a exposição de arte como um meio para "formar pensadoras aptas a articular cultura, exposições e instituições" (LAGNADO, 2015, p. 91).

Ter uma exposição como um meio para produzir e pensar a arte foi a nossa tarefa como professoras da disciplina e curadoras/propositoras da exposição. Lisette Lagnado (2015, p. 94) aponta que "a tarefa da curadoria se vale simultaneamente da liberdade do gesto artístico e de um projeto crítico, pois não há dúvida que a curadoria se configura como uma tentativa de criar espaços de leitura". Tais espaços de leituras podem ser compreendidos também como espaços de trocas, de mediação e de invenção. Espaços que ampliam o entendimento sobre a arte, a artista e as instituições. Milton Guran (2011) acrescenta que a curadoria pode estimular a reflexão tanto do público, quanto dos artistas, apontando caminhos e colocando novos pontos de vista. Nesse caso, o trabalho de 
curadoria se torna um catalisador de novas questões, aproximando-se muito do próprio ofício do artista, cujo trabalho se configura como um tipo de produção que carrega o potencial de transformar e provocar a vida, nos seus hábitos, naturalizações, costumes, regramentos e na sua regularidade (BASBAUM, 2016).

Esse tipo de efeito provocador e transformador foi algo que marcou nossa exposição/ocupação, uma marca que somente se fez presente pelo fato de termos assumido a curadoria também como uma proposição artística. Nossa intenção não era sermos um curador burocrata a serviço da demanda institucional, tampouco ser um curador corretor cultural que visa cobrir lacunas da história (OGUIBE, 2004). Nosso interesse era explorar o valor de exibição da arte como campo de criação de espaços de trocas. Buscamos nos alinhar a práticas curatoriais que desafiam os papéis tradicionalmente definidos dentro do sistema da arte. Inspiramo-nos em espaços de arte independentes, muitos deles criados pelas próprias artistas como forma de evitar o espaço tradicional do museu e, principalmente, colocarem-se como agentes ativos na definição de estratégias e formas de manifestações culturais e artísticas. De acordo com Oguibe (2004, p. 7), jovens curadores do final da década de 70 "puderam imaginar, iniciar e realizar experiências ousadas de curadoria, porque os artistas já haviam fornecido os exemplos que desafiavam a compreensão convencional da exposição e apresentação da arte".

Com uma verve mais artística e provocativa, o pensamento sobre curadoria também se renova e passa a entender os modos de exibição como forma de agenciar e intercruzar questões, de forjar novas alianças com o público e favorecer um arranjo de coisas que possibilitem experiências estéticas catalisando a relação entre obra, espaço, conceito e público. É nessa perspectiva que Jens Hoffmann (2004) afirma que a curadoria também pode ser concebida como um trabalho de arte, como uma proposição que mobiliza uma multidão de vozes e faz ver um nexo da arte que evidencia que esta "não é um sistema fechado, mas uma configuração de relacionamentos em constante mudança entre arte e realidade" (HOFFMANN, 2004, p. 20). É nesse jogo entre arte e realidade que a curadoria como proposição artística interfere diretamente, posto que não apenas comenta ou produz metáforas textuais ou visuais para uma dada realidade, mas forja e performa uma relação social. Para Hoffmann (idib., p. 21), o interessante nesse tipo de proposição curatorial se dá quando "a construção de uma exposição se encontra com a sociedade, em que cria uma relação em direção aos espectadores que lhes permite se tornarem sujeitos de suas próprias experiências". Falamos, portanto, da curadoria também como um conjunto de proposições vividas que seguirá reverberando como campo de experiências individual e coletivo. 
Outro conceito importante que merece ser aqui retomado é a ideia do artista-etc, de Ricardo Basbaum (2013). O autor, também artista e professor, cunha esse termo para retirar o artista do lugar de mero produtor de obra de arte e para situá-lo como um sujeito capaz de articular teoria, crítica, curadoria e história da arte. Para Basbaum, o artista contemporâneo se revela como um sujeito em trânsito, marcado por certo deslocamento entre papéis e pela inserção no sistema da arte de modo mais complexo e total. Para o autor, ao artista cabe "amplificar a atuação a partir de uma deliberada mistura de identidade" (BASBAUM, 2013, p. 68), que flerta com diferentes campos de conhecimento e também com diferentes campos de atuação, entre elas a curadoria.

Se, por um lado Oguibe (2004) e Hoffmann (2004) pontuam o quanto o campo da curadoria se transformou ao absorver a ousadia das práticas de certos artistas, com Basbaum aprendemos que ao artista cabe se engajar em todas as etapas de seu trabalho, da produção à exibição. A partir de suas contribuições, compreendemos também que ser artista-etc é problematizar os campos rígidos que segmentam o conhecimento e a prática artística. O fundo desse debate seria uma aproximação entre arte e vida que, tal como já sinalizado pela crítica institucional da arte, visa, entre outras coisas, diminuir a distância entre os trabalhos artísticos e o público.

A aproximação entre arte e vida foi também o que moveu nossa prática. Enquanto proposição artística a ocupação/exposição Presenças Plurais mobilizou vidas e desejos que fizeram o Espaço Ruínas pulsar intensamente por quatro dias e mais. Corpos circulavam no espaço, trocas aconteciam espontaneamente, sorrisos e um sentimento de pertencimento transbordava de todos que ali estavam. A potência do encontro fez desse acontecimento um trabalho de arte que aposta na exuberância da vida como forma de inventar realidades possíveis, para além daquelas que nos são dadas como estanques. Fomos movidos por uma força desejante que não se satisfez com a escassez do presente, que extraiu das ruínas uma potência para criar outros mundos, recuperando também nossa capacidade de sonhar, de imaginar e viver realidades outras.

Com um ímpeto inventivo na pele, pudemos viver uma experiência que revitalizou nosso território relacional, existencial, institucional e subjetivo. Pudemos experimentar uma conduta criadora diante do mundo que revela uma coextensividade entre o coeficiente artístico e o coeficiente vida (STUBS, 2019), entendido aqui como uma postura afirmativa diante da vida, que dá passagem às forças desejantes e aos territórios existenciais que nos são desconhecidos. Falamos então de operar ampliações no mundo, mesmo quando estas parecem ser da ordem do /im/possível. 


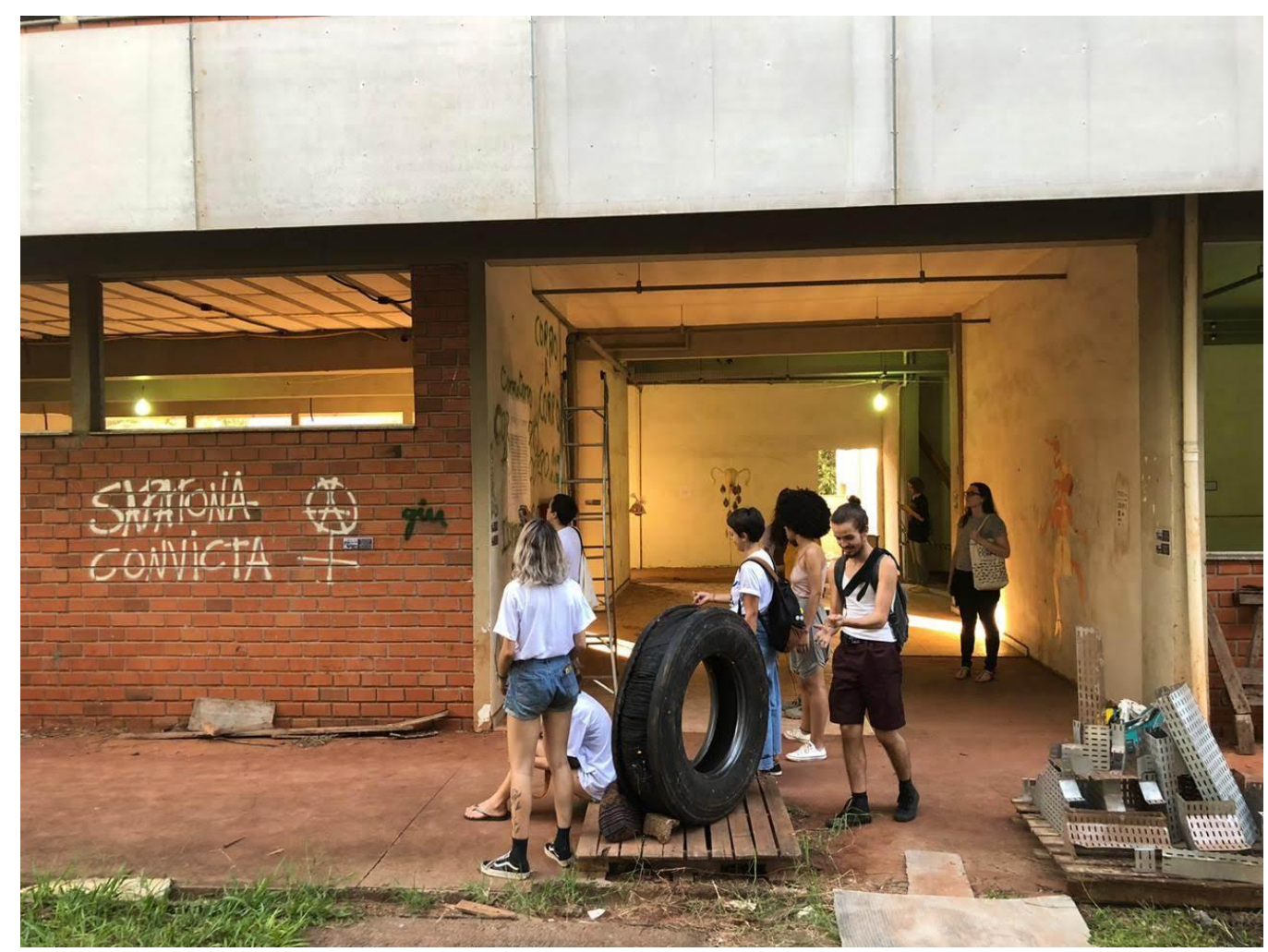

Figura 4: Alunos e alunas ocupando o Espaço Ruínas Fonte: Fernanda Magalhães, 2019. Arquivo pessoal das autoras.

\section{Conclusões e reverberações}

É possível dizer que a exposição/ocupação Presenças Plurais instaurou um lugar no qual o sonho, o desejo e as coisas que pareciam inviáveis pudessem se concretizar. Deu forma a forças que existiam apenas em potência. O Ruínas foi palco de uma espécie de partilha do sensível, tal como definida por Rancière (2005), pois intensificou a vida, as alianças e os afetos que ali ganharam corpo. Essas composições foram se desenhando com o fora, com forças exteriores à própria arte, na medida em que a arte é uma disciplina extremamente criadora e, como tal, mantém uma relação de escambo com domínios outros da criação.

Blocos de sensações foram insurgindo de cada ação atravessada pelas dimensões tangíveis/materiais e intangíveis/imateriais. Afetos e intensidades foram forças ativas no Espaço Ruínas, ecos e ressonâncias da atividade criadora que subjetivavam um devirartista-professora, que se desdobrou em uma ação pedagógica menor e micropolítica. Os acontecimentos agenciados por uma enunciação estavam paisagenzados sob as lentes de uma "educação menor" (GALLO, 2002, p. 172), na paisagem do esqueleto de um lugar 
abandonado, em escombros, expressa nas ações cotidianas de cada uma. Enquanto 'educação menor', nossa exposição/ocupação acabou por:

Insistir nessa coisa meio fora de moda, de buscar um processo educativo comprometido com transformações no status quo; insistir nessa coisa de investir num processo educativo comprometido com a singularização, comprometido com valores libertários (GALLO, 2002, p. 172).

A ação micro nos espaços educacionais e da arte se instaura como potências políticas, quando se articulam como uma guerrilha que desestabiliza os modos dominantes de organização, onde suas resistências atuam para a desestabilização das naturalizações normativas e colonizadoras. O espaço ruínas se apresentou como uma possibilidade de respiro em meio a projetos de educação cristalizados e engessados. A figura de artistaprofessora flerta com o devir revolucionário que se apresenta diante dos olhos, "no deserto de nossas escolas, na solidão sem fim - mas superpovoada - de nossas salas de aula não seremos, cada um de nós, cães e ratos cavando nossos buracos?" (GALLO, 2002, p. 170).

Ao saltarmos no horizonte /im/possível dessa exposição/ocupação, nosso desejo era atravessar o deserto de nossa instituição de ensino para povoá-lo com nossas especulações poéticas. Traçamos devires nômades no campus universitário e ocupamos o espaço com uma proposição artística com potencial revolucionário e coletivo. De acordo com Deleuze e Guattari (1999, p. 94), sob o ângulo da micropolítica, são as linhas de fuga, sempre moleculares, que definem uma sociedade, "sempre vaza ou foge alguma coisa, que escapa às organizações binárias, ao aparelho de ressonância, à máquina de sobrecodificação".

Por isso, nossas apostas são nas coisas que transbordam os endurecimentos institucionais e o definem pelo que dele escapa. Somos esses corpos que escapam, somos os desejos que pululam para além das amarras institucionais. É neste território que nos propomos a entrar em um devir artista-professora, em um "infinito compor-se, uma constante transmutação do ser professora. Tessituras em movimentos de desfeituras..." (SANTANA; SANTOS, 2015, s/p.). Um devir que se lança em encontros, que podem ser com pessoas, mas também com lugares, textos, ideias, imagens e devires. O Espaço Ruínas se tornou esse lugar para encontrar essa figura da artista-professora, mesmo sob uma ocupação temporária, constituindo-se como um caminho que nos lança a encontros com outros universos. O Ruínas, mediante curadoria, expografia, ações educativas, encontros, performances, aulas, forjou paisagens dentro de paisagens, as quais queríamos povoar e, em outros momentos, ser povoadas por elas em um ato de revolta e resistência: 
Revolta contra os fluxos instituídos, resistência às políticas impostas; sala de aula como trincheira, como a toca do rato, o buraco do cão. Sala de aula como espaço a partir do qual traçamos nossas estratégias, estabelecemos nossa militância, produzindo um presente e um futuro aquém ou para além de qualquer política educacional. Uma educação menor é um ato de singularização e de militância (GALLO, 2002, p. 173).

Pensamos em uma arte educação menor durante a ocupação e a criação do Espaço Ruínas para o contorno radical na formação dessas artistas-professoras e corpos plurais. Fomos atravessadas pela potência urgente dessa atividade na nossa atuação docente e nas nossas poéticas, algo que partiu de gestos singulares e muito potentes. Uma ocupação que surgiu dos devires minoritários, da margem, das exclusões institucionais e espaciais, que dá dupla evidência ao "agenciamento maquínico de desejo da educadora militante e agenciamento coletivo de enunciação, na relação com os estudantes e com o contexto social" (GALLO, 2002, p. 175).

É apostando no valor micropolítico de nossa exposição/ocupação que compartilhamos essa experiência artística que teve como força motriz um desejo coletivo de acontecer. Um desejo que corre neste texto e habita ainda o corpo de cada uma das pessoas envolvidas nesse projeto. Deleuze e Guattari (1995) afirmam que ser artista é lançar novas variações ao mundo, variações que possam seguir reverberando outras paisagens existenciais. Por forças institucionais maiores, a ocupação recebeu ordens para ser evacuada, assim o fizemos a contragosto. Porém, a força intangível desse acontecimento, segue ressoando. Como uma onda desejante, um lance para um devirartista do mundo, esperamos que o Espaço Ruínas se materialize em outros tempos e espaços concomitantes a esse que expusemos aqui. A arte foi e é vetor para que nosso desejo siga pulsando e inventando espaços de vida e resistência.

\section{Referências}

BAREMBLITT, G. Compêndio de Análise Institucional e outras correntes: teoria e prática. 5. ed. Belo Horizonte-MG: Instituto Felix Guattari, 2002.

BASBAUM, R. Manual do artista-etc. Rio de Janeiro: Azougue Editorial, 2013.

BASBAUM, R. Sobre o et cetera - Entrevista com Ricardo Basbaum. Revista Beira, v.2, n.2, 9 out. 2016. Disponível em: <https://medium.com/revista-beira/entrevista-comricardo-basbaum-85bbb4f0cea9>. Acesso em: 8 maio 2020.

BOIS, Y.-A. Mudança de cenário. In: HUTCHET, S. (org.) Fragmentos de uma teoria da arte. São Paulo: Editora da Universidade de São Paulo, 2012. 
BUREN, D. Função do Museu. In: DUARTE, P. S. (ed.). Daniel Buren: textos e entrevistas escolhidos (1967- 2000), Rio de Janeiro: Centro de Arte Hélio Oiticica, 2001.

EXPÓSITO, M. Arte como produção de modos de organização. Apresentação de Marcelo Expósito no Museu de Arte Contemporânea de Castilla y León, MUSAC, em 2014. Disponível em: <https://www.teses.usp.br/teses/disponiveis/27/27159/tde-04122018171845/publico/AnaEmiliaJungENCARTE1expositoONLINE.pdf>. Acesso em: 5 maio 2020.

DELEUZE, G.; GUATTARI, F. Mil Platôs (Capitalismo e Esquizofrenia). Tradução de Aurélio Guerra Neto e Célia Pinto Costa. v. 1. 1. ed. Rio de Janeiro: Editora 34, 1995.

DELEUZE, G.; GUATTARI, F. Mil platôs. v. 3. São Paulo: Editora 34, 1999.

DELEUZE, G; PARNET, C. Diálogos. São Paulo: Escuta, 1998.

FRASER, A. Da crítica às instituições a uma instituição da crítica. Concinnitas: Revista do Instituto de Artes da UERJ, Rio de Janeiro, v. 9, n.13, pp. 178-187, Maio/Maio, 2005.

FREIRE, C. Poéticas do processo. São Paulo: Iluminuras, 1999.

GUATTARI, F.; ROLNIK, S. Micropolítica: cartografias do desejo. Petrópolis/Rio de Janeiro: Vozes, 1996.

GALLO, S. Em torno de uma 'educação menor'. Revista Educação e Realidade. v. 2, n.2, p. 169 - 178, jul-dez. 2002.

GURAN, M. Curadoria: expressão e função social. Studium, n. 32, p. 90-93, inverno 2011. HOFFMANN, J. A exposição como trabalho de arte. Revista Concinnitas, v. 1, n. 6, p. 18$30,2004$.

JUNG, A. E. Arte Ocupação: práticas artísticas e a invenção de modos de organização. São Paulo: USP, 2018. Tese (Doutorado em Poéticas Visuais). Universidade de São Paulo, 2018.

LAGNADO, L. Por uma revisão dos estudos curatoriais. POIESIS, v. 16, n. 26, p. 81-97, 2015.

LIPPARD, L. R.; CHANDLER, J. A desmaterialização da arte. Arte \& ensaios, n. 25, p. 180193, 2013.

OGUIBE, O. O fardo da curadoria. Revista Concinnitas, v. 1, n. 6, p. 6-18, 2004.

RANCIÈRE, J. A partilha do sensível: Estética e política. Tradução de Mônica Costa Netto. São Paulo: Editora 34, 2005.

ROLNIK, S. Geopolítica Da Cafetinagem, 2006. Disponível em: $<$ http://www4.pucsp.br/nucleodesubjetividade/Textos/SUELY/Geopolitica.pdf $>$. Acesso em: 8 maio 2020.

SANTANA, A. F. T. \& SANTOS, A. C. Um possível olhar acerca dos elementos que compõem o ser professor. In: Encontro Internacional de Formação de Professores e Fórum Permanente de Inovação Educacional. 2015, Sergipe. Anais do 8 Encontro Internacional de Formação de Professores e Fórum Permanente de Inovação Educacional: Unit, $2015 . \quad \mathrm{s} / \mathrm{p}$. Disponível em: 
<https://eventos.set.edu.br/index.php/enfope/article/view/1172>. Acesso em: 8 maio 2020.

STUBS, R. O /im/possível como coeficiente artístico. Revista Visuais, v.5, n.1, pp. 79105, 2019. Disponível em: <https://doi.org/10.20396/visuais.v5i1.12137>. Acesso em: 5 maio 2020.

STUBS, R.; MADDOX, C. Exposição Presenças Plurais. In: I Seminário de Artes Visuais da UEM. Corpo a corpo: Presenças Plurais. Universidade Estadual de Maringá - UEM. Anais eletrônicos. Maringá, PR: UEM, 2019. Disponível em: http://sites.uem.br/arv/catalogoexposicao-ocupacao-presencas-plurais.pdf. Acesso em: 7 março 2020.

TIQQUN. Como fazer? Como Desertar? São Paulo: N-1 Edições, 2019.

\begin{abstract}
' Artista, pesquisadora e psicóloga com doutorado em psicologia com ênfase em arte, gênero e produção de subjetividade pela Universidade Estadual Paulista (Unesp) de Assis. Possui graduação em Psicologia pela Universidade Estadual de Maringá (2005), especialização em Saúde Mental e mestrado em História da Educação pela mesma instituição. Líder do DOBRA - Grupo de Pesquisa em Arte, Subjetividade, Educação e Diferença. Professora do curso de Artes Visuais da Universidade Estadual de Maringá. Com trabalhos em fotografia, vídeos, instalações e objetos, a artista tem explorado temas como o corpo, o tempo, a memória, o vazio e o transbordamento subjetivo. Possui experiência na área de psicologia, arte contemporânea e gênero, com ênfase em processos de subjetivação na contemporaneidade e políticas inventivas da vida.

ii MADDOX é Cleberson Diego Gonçalves. Doutorando em Educação na Universidade Estadual de Maringá - UEM. Mestre em Educação pela Universidade Estadual de Maringá UEM. Especialista em Gênero e Diversidade na Escola pela Universidade Federal do Paraná (UFPR). Graduado em Artes Visuais, artista e Professor Assistente do Departamento de Teoria e Prática da Educação da Universidade Estadual de Maringá - UEM. Atua nas linhas de arte decolonial, subjetividades e sexualidade no grupo de pesquisa NUDISEX - Núcleo de Estudos e Pesquisas sobre Diversidade Sexual, e atua em Estéticas decoloniais, poéticas subversivas, dissidências e decolonização do pensamento no grupo DOBRA - Grupo de Pesquisa em Arte, Subjetividade, Educação e Diferença.
\end{abstract}

Como citar esse artigo:

STUBS, Roberta; GONÇALVES, Cleberson Diego. Espaço Ruínas: do valor de exibição para o valor de ocupação/acontecimento. Revista Digital do LAV, Santa Maria: UFSM, v. 14, n. 1, p. 06-25, jan./abr. 2021. 